\title{
Passaretti, Rehn, and Schaefer to Chair 1991 MRS Spring Meeting
}

June D. Passaretti, Lynn E. Rehn, and Dale W. Schaefer will chair the 1991 MRS Spring Meeting scheduled for April 27 - May 1, 1991 in San Francisco, California. A full roster of symposia is being planned.

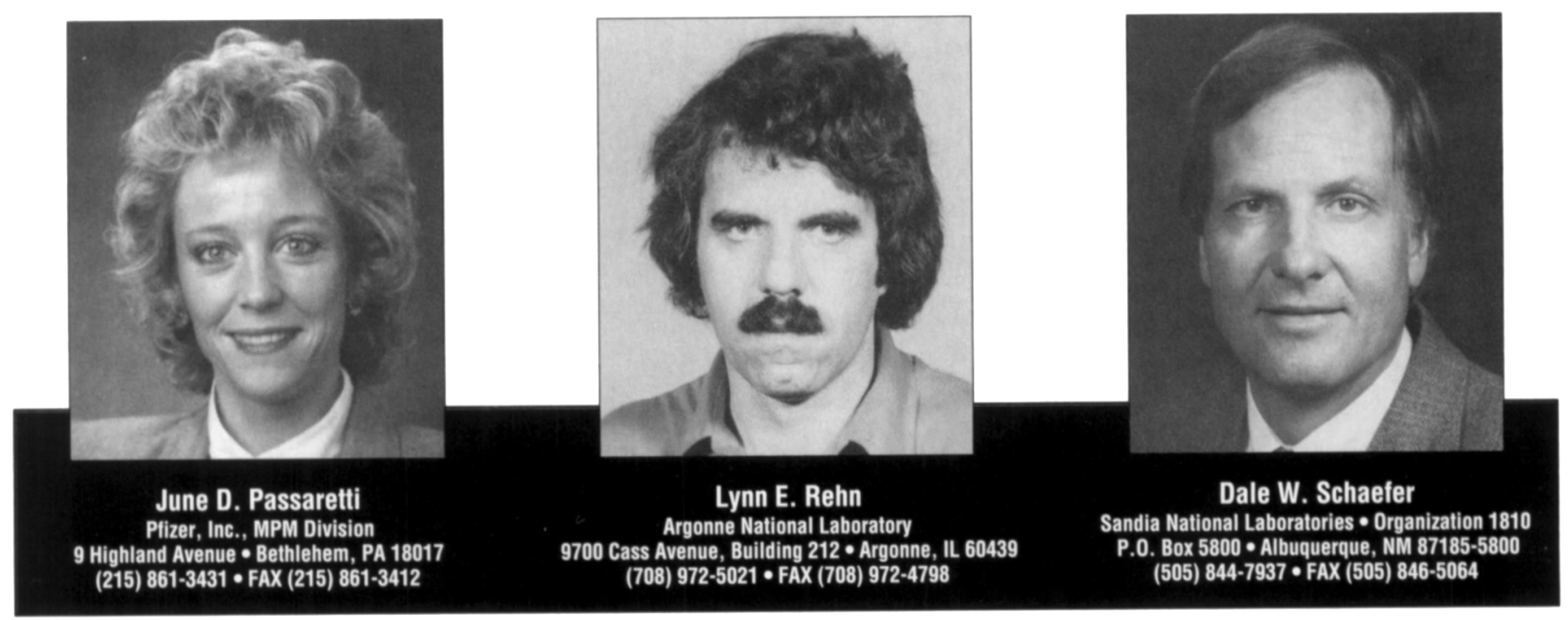

June D. Passaretti heads a New Product Development Laboratory at Pfizer Specialty Minerals, where she has been since 1987. She received a BA in chemistry from William Paterson College in New Jersey and a PhD in chemistry from Brown University. Before joining Pfizer she was a member of the staff at Exxon Corporate Research Laboratories. Passaretti's research efforts have focused on the synthesis and characterization of inorganic materialsand the relationship between the morphology of these materials and their function in applications such as catalysis and paper making. She is a member of the American Chemical Society, Technical Association of the Pulpand Paper Ind ustries as well as the Materials Research Society. Passaretti co-chaired the MRS symposium on "Materials Interactions Relevant to the Pulp, Paper, and Wood Industries" (Spring 1990), and for the past three years she has chaired the MRS Public Relations and Publicity Committee.

Lynn E. Rehn heads the Irradiation and Kinetic Effects Group in the Materials Science Division at Argonne National Labora- tory. He received a $\mathrm{BA}$ degree (1967) from Albion College in Michigan and a PhD (1973) in physics from the University of Illinois at Urbana-Champaign. During 1970-71 he served with VISTA in Gary, Indiana, and from 1973-76 was a member of the scientific staff at the Kernforschungsanlage (Nuclear Research Center) in Jülich, Germany. He is an associate editor for Applied Physics Letfers, and currently serves on the editorial advisory boards for the Journal of Nuclear Materials, and for Nuclear lnstruments and Methods in Physical Research: B. Rehn's primary research interests include fundamental irradiation effects, ion-beam analysis and modification, solid-state amorphization, and high-T lattice instabilities. He was a cowinner of the 1984 DOE award for Outstanding Sustained Research in Metallurgy and Ceramics, and has co-chaired two MRS symposia, "Fundamentals of Beam-Solid Interactions" (1987 Fall Meeting) and "Processing and Analysis of Materials Using Ion Beams" (1988 Fall Meeting).

Dale W. Schaefer has been the manager of the Organic and Electronic Materials De- partment at Sandia National Laboratories since 1989. Previously he supervised the Chemical Physics and Corrosion Divisions at Sandia. Schaefer's research interests cover disordered materials, ceramic and polymer materials science, colloid physics, and combustion aerosols. He is currently using inelastic neutron scattering to study the vibrational dynamics of glasses. Schaefer has a BS in chemistry from Wheaton College (Illinois) and $\mathrm{PhD}$ in physical chemistry from the Massachusetts Institute of Technology. Before joining Sandia he was an IBM research associate in Yorktown Heights, New York. He is a Fellow of the American Physical Society and the American Institute of Chemists. He is a member of the American Chemical Society, the American Ceramic Society, and the American Association for Aerosol Research as well as the Materials Research Society. In 1986, he received the DOE-Basic Energy Sciences Outstanding Sustained Research Award. Schaefer coorganized the MRS symposium on "Fractal Aspects of Materials" in 1986 and the symposium on "Polymer-Based Molecular Composites" in 1989.

\section{SYMPOSIUM TOPICS IN THE PLANNING FOR THE 1992 MRS SPRING MEETING}

- Amorphous Silicon Chemical Surface Preparation, Passivation and Cleaning for Semiconductor Growth and Processing - Advanced Metallization and Processing for Semiconductor Devices and Circuits II $\boldsymbol{a}$ Photo-Induced Space Charge Effects in Semiconductors:

Photoconductivity, Spectroscopy and Electrooptics Defect Engineering in Semiconductor Growth, Processing and Device Technology Heterostructures

- Electronic Packaging Materials Science VI - Macromolecular Host-Guest Complexes: Optical and Optoelectrical Properties and Applications

- Smart Materials Fabrication Computational Methods in Materials Science Art \& Archaeology III Materials Modification by Energetic Atoms and lons

- Microwave Processing $\square$ Novel Forms of Carbon B Better Ceramics Through Chemistry V a Aerosol Precursors to Materials

- Layered High-T. Superconductors: Fabrication. Properties, and Applications $\mathbf{U}$ Structure and Defects in Electronic Ceramic Oxides

- Materials Interactions Relevant to the Recycling of Wood-Based Resources $\mathbf{m}$ Materials for Energy Technologies $\mathbf{m}$ Materials for Separation Technology $\boldsymbol{\square}$ Intermetallic Matrix Composites II Submicron Multiphase Materials Frontiers of Materials Science

Materials for Micro-Electro-Mechanical Systems $\mathbf{E}$ Chemical Processes in Inorganic Materials: Metals \& Semiconductors-Clusters and Colloids 